\title{
Adult mental health services and the collaboration with child protection services
}

\author{
Camilla Lauritzen, Charlotte Reedtz \\ Regional Center for Child and Youth Mental Health \& Child Welfare (RKBU North), UiT-Arctic University of Norway, Norway
}

Received: February 24, 2016

DOI: $10.5430 /$ jha.v5n5p72
Accepted: April 25, 2016

URL: http://dx.doi.org/10.5430/jha.v5n5p72

\begin{abstract}
Parental mental illness may increase the likelihood of neglect and abuse, and is also a potent risk factor in terms of offspring developing mental health problems themselves. Collaboration between the adult mental health services (AMHS) and the child protection services (CPS) has the potential of reducing risk for the children, by using family supporting interventions and making help available at an earlier stage. The aim of this study was to explore the collaboration between the CPS and the AMHS in terms of routines, attitudes and knowledge. Data was gathered using electronic survey questionnaires. Several barriers to inter-service collaboration were identified in this study. Even though adult mental health professionals were positive towards the CPS, they were reluctant to refer cases of concern. They also lacked knowledge about the CPS. Conclusion: The results indicate that there is an unresolved potential for inter-service collaboration involving the children of patients with mental health problems.
\end{abstract}

Key Words: Collaboration, Adult mental health services, Child protection services, Parental mental illness, Prevention strategies

\section{INTRODUCTION}

The causes of child neglect are complex; however, studies suggest that parental mental health problems increase the likelihood of neglect and abuse. ${ }^{[1]}$ Even though there is no single description that captures all families in which children are victims of abuse and neglect, parental mental illness is frequently associated with maltreatment across studies. ${ }^{[2]}$

Parental mental illness is a serious problem for children and families throughout the world. Several international studies have documented parental mental illness as a powerful riskfactor and substantial documentation exists on the serious effects parental mental illness may have on the early developmental stages of a child's life. ${ }^{[3-7]}$ Parental mental illness has the potential of development of a variety of problems in offspring. These children run a higher risk of abuse and neglect, depression, anxiety disorders, substance abuse, eating disorders, conduct problems and academic failure ${ }^{[8,9]}$ In school, these children are likely to have impaired abilities to behave in class, to pay attention and retain knowledge. ${ }^{[10]}$ These factors will likely contribute to academic problems and school dropout, in addition to reduced quality of life. ${ }^{[11]}$ Preventive interventions aiming to decrease the risk of mental disorders in the offspring of mentally ill parents have been found to be effective. ${ }^{[12]}$

One third of all minors have been estimated to have a parent with mental illness. ${ }^{[13,14]}$ Between $44 \%-74 \%$ of these children develop psychosocial or mental health problems. ${ }^{[7]}$ Parental mental illness is therefore considered a potent risk factor for children's development, and more than one third of these children develop serious and long-lasting problems. ${ }^{[15]}$

\footnotetext{
*Correspondence: Camilla Lauritzen, Assoc. Prof.; Email: Camilla.Lauritzen@uit.no; Address: Regional Center for Child and Youth Mental Health \& Child Welfare (RKBU North), UiT- Arctic University of Norway, Norway.
} 
The primary task of the Norwegian Child Protection Service (CPS) is to protect children from all kinds of abuse and neglect, as well as to prevent risks associated with such conditions. According to Norwegian laws on child protection, people or institutions bound by the professional duty of confidentiality are required to report cases of concern to the CPS. ${ }^{[16]}$ This applies, for example, to doctors, psychologists, nurses, midwives and schoolteachers. The CPS is obligated to investigate every report of concern they receive. However, the group reporting concerns most frequently, are parents themselves. Problems often tend to be quite severe when others report a case to the CPS. According to the Norwegian Directorate for Children, Youth and Family Affairs, in most cases it would have been a great advantage if the CPS had been contacted earlier, because severe impact on the child's developmental path could have been prevented. ${ }^{[17]}$

Children who have been exposed to maltreatment, neglect and/or abuse due to parental mental illness are in many cases invisible to the CPS. ${ }^{[18]}$ The adult mental health services (AMHS) are in a key position to discover children at risk for maltreatment and neglect, since they are the ones who treat parents with mental health issues. To improve the identification of children who are in need of support and intervention, several modifications were made to health legislation. ${ }^{[19]}$ It is now mandatory for health professionals to register and to provide necessary follow-up for children under 18 years who have parents that receive health care for mental illness. Provision of follow-up should be planned in collaboration with the patient, and is depending on parental consent. The information about the children is supposed to be recorded in the patient's electronic patient journal, and reported to relevant collaborating agencies such as kindergartens, schools, school nurses and the CPS. Collaboration is therefore not just necessary to prevent neglect, abuse and mental health problems in children of mentally ill parents. It is also clearly expressed by the Norwegian authorities that inter-professional and interservice collaboration should be a priority.

In one of our previous studies we calculated that $35 \%$ of the patients in the participating clinic were parents of one or more minor children. ${ }^{[18]}$ In 2012, a total of 5,705 patients were treated in the clinic, and hence about 1996 of these had one or more minor children. However, we found that only 395 patients were registered with children. This was interpreted as a strong tendency to skip the identification of patients' children. There is also reason to believe that the professional collaboration between AMHS and the CPS is unsatisfactory. According to Statistics Norway, 52,553 reports about children at risk were received in 2013 by the CPS in Norway. Only 714 (1.4\%) of these came from the adult mental health services. The reasons for the lack of collabora- tion between these two agencies are probably multi-factorial. Several barriers to inter-professional collaboration were detected in a study carried out by Darlington and colleagues in 2005. These barriers were linked to different factors such as; inadequate resources, confidentiality, gaps in interagency processes, unrealistic expectations, and professional knowledge. ${ }^{[20]}$

Internationally, it is recognized that underdeveloped and inefficient inter-professionalism may cause poor outcomes for service users. ${ }^{[21]}$ Based on this, it is likely that children of mentally ill parents and their families, will benefit from a functioning collaboration between AMHS and CPS. There are however few studies assessing the collaboration between the AMHS and the CPS in terms of attitudes, knowledge and collaboration routines. The aim of the current study was therefore to explore the extent AMHS in Norway collaborated with the CPS. A second aim was to explore barriers to collaboration between the two agencies. Finally, our aim was to explore attitudes and knowledge within the mental health care services about the CPS.

\section{METHOD}

\subsection{Participants}

Participants in this study were the staff and leaders at a large, regional university hospital in Norway. There were 16 outpatient and inpatient clinics participating, serving a large geographical area of 31 municipalities. The total workforce, including 436 participants, was asked to answer an electronic questionnaire. A total of 185 individuals responded, representing a response rate of $40.5 \%$. The respondents were $67 \%$ women, of which the majority was between 30 to 50 years old. The participants worked in interdisciplinary treatment teams, and had a variety of different educational backgrounds, e.g., nurses, enrolled nurses, psychologists, psychiatrists, occupational therapists and special teachers.

\subsection{Measures}

The questions were based on the Family Focused Mental Health Practice Questionnaire. ${ }^{[22]}$ The measure has been evaluated in Australia, where they found it had good psychometric qualities and served as a useful tool to evaluate services for families. ${ }^{[22]}$ The questionnaire was adapted to a Norwegian context to assess regular practice in dealing with children of mentally ill parents at the participating hospital both prior and subsequent to the implementation of new interventions.

\subsubsection{Demographic and work characteristics}

Personal demographic variables included age, gender and education, in addition to single items on work characteristics such as leadership responsibilities and current position. 


\subsubsection{Collaboration between the adult mental health and CPS}

Five questions were included to study the extent of collaboration between the AMHS and the CPS. The questions were: (1) Have you or members of your treatment team reported concerns to the CPS regarding patients' children during the past 6 months? (yes, no, don't know); (2) Have you or members of your treatment team considered reporting concerns to the CPS regarding patients' children during the past 6 months, but chosen not to? (yes, no, don't know); (3) What was the reason for the decision not to report to the CPS? (open); (4) Does your treatment team collaborate with the CPS regarding children of your patients today? (yes, no); (5) How well on a scale from $1=$ very little to $5=$ very large do you experience the collaboration is between the Adult mental health and the Child protection services?

\subsubsection{Attitudes to the CPS}

Attitudes to investigate the adult mental health workers' attitudes towards collaboration with the CPS were measured with four items. The items were: AMHS should initiate collaboration with the CPS in the patient's local community, AMHS personnel should report concerns about the patients' children to CPS, Reporting concerns to the CPS may interrupt the treatment alliance between therapist and patient, and The treatment alliance between therapist and patient may be interrupted if health personnel collaborate with CPS in interventions. The items were answered on a five point Likert-scale as follows: To what extent do you agree/disagree with the statements on a scale from $1=$ strongly disagree $-5=$ strongly agree .

\subsubsection{Knowledge about CPS}

Two items were included to investigate the knowledge of the AMHS about the formal obligation to report to the CPS and the interventions and methods available for the patients' children within the CPS. The items were: To what extent do you know about health care workers' duty to report concerns to the CPS? And How would you describe your knowledge about the interventions and methods available for patients' children within the CPS? The items were answered on a five point Likert-scale from $1=$ Very little, $2=$ Little, $3=$ Neither/nor, $4=$ Large, and $5=$ Very large.

\subsection{Procedure}

This cross-sectional study is part of an on-going longitudinal project that assesses clinical practice in terms of identification and follow-up of children of mentally ill parents in Norway. The data was gathered in 2013, between April and June. The mental health workers in the clinic were invited to respond to web-based questionnaires via email. Email lists were made available to us by the management of the clinic as part of the collaboration with our research group. Participation was, however, voluntary, as prescribed in the Helsinki declaration. ${ }^{[23]}$ Information about this and about the project in general was provided in the invitation to participate.

Electronic survey questionnaires were used (Quest Back), and the questionnaires were completed anonymously. The study was approved by the Data Protection Supervisor at the University Hospital of Northern Norway, and was conducted in line with the Helsinki Declaration of Ethical Principles for Medical Research Involving Human Subjects published by the World Medical Association.

\subsection{Data analyses}

The data was exported from Quest Back to SPSS. Descriptive analyses were used to explore the research questions. Pairwise missing was used for descriptive analyses. In general, the data set had few missing values.

The open ended item regarding reasons not to report to the CPS was coded manually, and analyzed using a qualitative technique called Framework Analysis. ${ }^{[24]}$ Framework Analysis has 5 key stages; familiarisation, identifying a thematic framework, indexing, charting and interpreting. The familiarisation is when the transcription and reading of the data took place. The data material was systematised, and the process of initial coding took place, developed both from emerging issues and from pre-existing questions based on existing research and theory. The data was consecutively coded into themes, and the next part of the analysis process was charting. In the charting process the data was thematically organized in matrixes, forming the basis of tables to interpret. The final stage of analysis was the interpretation stage. The data was systematically explored to reveal relevant explanations and associations linked to the research question.

\section{RESULTS}

The results showed that less than half of the staff had reported concerns about a patients' child to the CPS (46.5\%). Additionally, $21.1 \%$ of the staff had considered reporting concerns to the CPS, but chose not to. An overwhelming $71.4 \%$ of the staff said they had no current collaboration with the CPS. In terms of collaboration between the AMHS and the CPS, the respondents were also asked to rate the quality of the collaboration. The majority of the respondents $(43.4 \%)$ rated the quality of the collaboration as "neither good nor bad". A total of $37.8 \%$ rated the collaboration as good or very good, while $6.9 \%$ rated the collaboration as poor or very poor. A total of $11.9 \%$ stated they did not collaborate with the CPS in general. The second aim of this study was to explore the barriers within the AMHS to col- 
laborate with the CPS. We included an open ended item in our questionnaire in order to tap out the respondents' own viewpoints in terms of why they chose not to refer cases to the CPS. A total of 34 adult mental health workers chose to report on this item. The results showed four main barriers within the AMHS: insecurities, sufficient intervention, disagreement, and insufficient information. Insecurities were related to assessing whether or not there were grounds for referring to the CPS. They were also uncertain about their responsibilities as health care workers in terms of referring cases. Furthermore, they were uncertain about the actions the CPS would take and which consequences CPS involvement would have for the families. Some were also uncertain about the consequences for the continued relationship with the patient after having referred the patient's children to the CPS. Finally, some were uncertain about the competence and quality of work within the CPS, and expressed skepticism about referring cases in general. The second main barrier to collaboration and referrals was related to the idea that there was already sufficient intervention or sufficient care for the child. The respondents stated that the child was safeguarded to a satisfactory degree in cases where other agencies (e.g., school nurses) were involved. Some also believed that as the parent was in treatment, no additional measures needed to be taken regarding the child, implying that the parent would benefit enough from the treatment to be an adequate parent. The third barrier was linked to disagreement, and mainly referred to the treatment teams having different opinions as to when a case should be reported to the CPS. In some cases there was also disagreement with the parent, who opposed contact with the CPS, and some reported this as a valid reason for not referring cases. The final barrier was reported to be insufficient information. Many respondents did not want to involve the CPS because they lacked information. They believed it was difficult to obtain sufficient information about the child's well-being solely based on the treatment of the patient. They also reported they had many unclear cases, where they found it difficult obtaining information about the situation at home in the family, e.g., divorced families and new partners involved. In many cases they said they might have a feeling that the child could be at risk, but had no means of knowing for sure. See Table 1 for an overview of barriers to collaboration.

Table 1. Barriers within AMHS to collaboration and referrals to CPS $(\mathrm{N}=34)$

\begin{tabular}{|c|c|c|c|}
\hline Insecurities & Sufficient intervention & Disagreement & Insufficient information \\
\hline $\begin{array}{l}\text { Unsure whether there were } \\
\text { grounds }\end{array}$ & $\begin{array}{l}\text { The child was cared for by another } \\
\text { caregiver }\end{array}$ & $\begin{array}{l}\text { Disagreement within personnel group } \\
\text { whether there were grounds to report to CPS }\end{array}$ & $\begin{array}{l}\text { Insufficient information about the } \\
\text { child's condition }\end{array}$ \\
\hline $\begin{array}{l}\text { Uncertainty. Afraid that it was } \\
\text { wrong }\end{array}$ & $\begin{array}{l}\text { The case was already known by the } \\
\text { CPS }\end{array}$ & $\begin{array}{l}\text { Patient opposed the initiative to contact the } \\
\text { CPS }\end{array}$ & Difficult to assess unclear cases \\
\hline $\begin{array}{l}\text { Difficult to assess unclear cases. } \\
\text { You may assume the child } \\
\text { suffers, but you are not sure }\end{array}$ & $\begin{array}{l}\text { Other agencies were involved, the } \\
\text { child was considered taken care of }\end{array}$ & & $\begin{array}{l}\text { Have a hunch that the child may } \\
\text { be at risk, but don't know the } \\
\text { details in the family }\end{array}$ \\
\hline $\begin{array}{l}\text { Uncertainty as to the } \\
\text { consequences for the family }\end{array}$ & $\begin{array}{l}\text { The patient was getting better, and } \\
\text { more capable to care for the child }\end{array}$ & & \\
\hline Uncertainty about responsibility & $\begin{array}{l}\text { The school nurse was involved, } \\
\text { considered to be sufficient }\end{array}$ & & \\
\hline $\begin{array}{l}\text { Uncertain about the competence } \\
\text { within the CPS }\end{array}$ & $\begin{array}{l}\text { Assessed the situation of the child } \\
\text { to be adequate }\end{array}$ & & \\
\hline $\begin{array}{l}\text { Uncertain about consequences } \\
\text { for the treatment alliance }\end{array}$ & & & \\
\hline
\end{tabular}

To understand the barriers to collaboration better, we also wanted to explore the attitudes about the CPS within the adult mental health services. The attitudes toward establishing contact between the CPS and the patient were positive $(\mathrm{M}=4.06)$. The Adult mental health workers also had positive attitudes in terms of referring cases to the CPS $(M=4.29)$. In terms of attitudes regarding collaboration and referrals to the CPS in relation to the treatment alliance between patient and therapist, the results were more negative. Several mental health workers reported that they believed collaboration with the CPS would negatively affect the re- lationship with the patient $(M=2.85)$, and that referring cases to the CPS would have a negative impact on the patienttherapist relation $(\mathrm{M}=3.23)$.

The adult mental health workers' knowledge about CPS was also assessed. The results showed that the majority of the adult mental health workers were aware of the formal obligation they had in terms of referring cases to the CPS $(\mathrm{M}=4.04)$. In terms of knowledge about the CPS' content: i.e., interventions and methods, the mean score was lower $(\mathrm{M}=3.15)$, indicating a lack of knowledge about the services that can be offered by the CPS (see Table 2). 
Table 2. Adult mental health services attitudes and knowledge about the CPS $(\mathrm{N}=185)$

\begin{tabular}{|c|c|c|}
\hline & $\mathbf{M}$ & $S D$ \\
\hline AMHS should initiate contact between CPS and patients who are parents & 4.06 & 0.86 \\
\hline AMHS Should report concerns about the patients' children to the CPS & 4.29 & 0.93 \\
\hline The treatment alliance will be negatively affected if the AMHS report to the CPS & 3.23 & 0.95 \\
\hline The treatment alliance will be negatively affected if the AMHS collaborate with the CPS & 2.85 & 0.89 \\
\hline *Knowledge about obligation to report to the CPS & 4.04 & 0.92 \\
\hline *Knowledge about interventions and procedures within the CPS & 3.15 & 0.90 \\
\hline
\end{tabular}

Note. Attitudes were scored: $1=$ strongly disagree to $5=$ strongly agree; ${ }^{*}$ Knowledge was scored: very little $=1$ to very large $=5$

\section{Discussion}

A total of $46.5 \%$ of the staff said they had reported concerns to the CPS during the past 6 months, whereas $52.4 \%$ said they had considered reporting concerns to the CPS but chosen not to. In terms of collaboration, $21.6 \%$ stated that they collaborated with the CPS at the time of the survey. The majority of the respondents $(43.2 \%)$ rated the quality of the collaboration as "neither good nor bad".

At first glance, it may seem like many cases are being referred from the AMHS to the CPS. However, mental health workers who have reported concern to the CPS, may refer to the same cases in our survey, which reduces the total amount of children referred to the CPS. Furthermore, compared to the low number of cases the CPS actually receives from the AMHS (only $1.4 \%$ of all the referred cases), there is still reason to believe that many children are lost for follow up. More than half of the staff said they had considered reporting concerns to the CPS but chosen not to. This may be seen as evidence to the statement that there are many barriers within the AMHS in terms of referring cases to the CPS. ${ }^{[20]}$

In terms of actual collaboration, $21.6 \%$ stated that they collaborated with the CPS at the time of the survey. Considering the fact that parental mental illness is a potent risk factor, this area of collaboration therefore seems underdeveloped. In a prevention perspective, there is an unfulfilled potential of developing the collaboration for children of mentally ill parents. ${ }^{[21]}$

The majority of the respondents (43.2\%) rated the quality of the collaboration as "neither good nor bad". In the questionnaire, the option of "not applicable" was available, so the response should not refer to the collaboration being nonexistent. We believe the results may be interpreted as an indication of collaboration being limited to contact between the services as the case is referred from an adult mental health worker to a child protection worker. Substantial collaboration should involve more than just handing over a case, and rating the collaboration as good or bad therefore seems unsuitable. This interpretation is however just an assumption, and should be investigated in future studies.
Several barriers to refer cases to and collaborate with the CPS were discovered within the adult mental health services. One of the main barriers was linked to insecurities. In summary, this barrier can be seen in relation to assessment of the quality of care the child receives. It seems like workers in AMHS are insecure about assessing whether or not there are grounds to report to the CPS. This is a common misinterpretation of the duty to report to the CPS in Norway. Although a professional working with children and families is obligated by law to report cases to the CPS when there may be reasons to believe the child is at risk, the professional does not have the responsibility to assess if there are valid grounds for their concerns. The CPS will make this assessment. However, many adult mental health workers seem to think they have to assess whether or not the child really needs assistance from the CPS or not before they report concern. In general, we believe this indicates of a lack of knowledge about the CPS within the adult mental health services. Another interpretation is that workers within the AMHS lack confidence in the CPS. This seems represented in the finding that some workers are uncertain about the competence within the CPS, and raise concerns about the quality of the work within these services. One way of addressing the barrier of insecurity is to increase the knowledge the services have about each other. When we assessed knowledge about the CPS in this study we did find that the adult mental health workers had adequate knowledge about their formal obligation to report cases. There was however a large group of the personnel who said they had little knowledge about how the CPS actually operates and what kinds of interventions are available for children of patients and their families. This supports the idea that in order to successfully collaborate about children of mentally ill patients, the different services need to attain better knowledge of each other and this may involve establishing arenas for collaboration. Nevertheless, only $18.3 \%$ of the respondents chose to report on barriers to collaboration. We believe this can be interpreted as a lack of awareness between the adult mental health workers in terms of collaboration with the CPS. If adult mental health workers are unaware of their responsibility to contact the CPS, they 
are not likely to have reflected on any barriers either.

The final aim of this study was to assess attitudes to the CPS within the AMHS. In terms of attitudes, the AMHS were generally positive about referring cases and collaborating with the CPS. This is however in contrast to the relatively modest number of cases being referred yearly to the CPS. We believe the reason for this gap between good intentions and actual practice must be seen in relation to the barriers we detected. Yes, the AMHS believe it is a good idea to collaborate with the CPS, but they have a lot of reservations and perhaps some prejudice in that manner. This should be further investigated in future studies.

In terms of attitudes related to the CPS interfering with the treatment alliance between therapist and patient, the results were not positive at all. A total of $40.5 \%$ of mental health workers believed that reporting cases to the CPS would have a negative impact on their relationship with the patient, and $42.7 \%$ were neutral to this. Only $15 \%$ disagreed with this statement. This is a major issue, because if you believe that involving the CPS will interfere with the treatment you are providing for the patient, and potentially reduce the effects of the treatment, it is probably less likely that you will approach the CPS when you are concerned about a patient's child. Furthermore, services from the CPS may represent an important recourse for patients and their families. In fact, 8 out of ten interventions offered by the CPS are supportive services aimed to prevent hardship on behalf of the children. In addition, 8 out of 10 parents are very satisfied with the services provided by the Norwegian CPS. Additionally, involving the parenting issues in the treatment situation has been found to increase the effectiveness of the treatment compared to situations where parental issues were not brought up. ${ }^{[25]}$ In terms of preventing parental mental illness transmitting to the next generation, we believe that the reluctance to address the parenting role in treatment within the AMHS is an issue that must be overcome within these services.

\section{Limitations}

One limitation is the fact that the analyses in this study are strictly descriptive, describing the basic features of this field.
Future studies should include inferential analyses to investigate the hypothesis that there is a large potential for better collaboration between AMHS and CPS, or to predict factors of importance for collaboration.

The study also relied solely on self-report measures for attitudes, knowledge, and current work practice. Alignment with national measures conducted by Statistic Norway showed a great discrepancy between referrals nationally and selfreported referrals in our sample. Future studies should look into objective measures from the participating clinic, to compare with the self-report data.

Another limitation is the relatively modest response rate of this study (40.5\%). This may bias the results if the decision to participate is related to worker attitudes, e.g., that those who are already positive about collaboration with the CPS about the children of their patients are more likely to participate. One consequence of this may be that this article presents the attitudes within the workforce as more positive than what they really are. Future studies should also include other explanatory variables to get a bigger picture of the hindering factors related to involving the children of patients who are parents. This may include both individual characteristic as well as organizational variables.

\section{Conclusions}

The potential of making a difference for children at risk of neglect or abuse due to parental mental illness is large. This however requires a functional collaboration between the services treating the parent and the CPS. This study showed that the potential is underdeveloped. Even though the AMHS had positive attitudes about the CPS, they had limited knowledge about how the CPS could assist them when patients were parents. Future studies should investigate the topic further.

\section{Implications for practice}

Systematic work to reduce barriers within the AMHS to refer cases and establish collaboration with the CPS is needed.

\section{CONFLICTS OF INTEREST Disclosure}

The authors declare they have no conflicts of interest.

\section{REFERENCES}

[1] Daniels B. Introduction to Issues for Health and Social Care in Neglect. In Taylor \& Daniel (eds) Child Neglect: Practice Issues for Health and Social Care. London \& Philadelphia: Jessica Kingsley Publishers; 2005. 11-25 p.

[2] Goldman J, Salus MK, Wolcott D, et al. A Coordinated Response to Child Abuse and Neglect: The Foundation for
Practice. Office on Child Abuse and Neglect. 2003. Available from: https://www.childwelfare.gov/pubs/usermanuals/ foundation/index.cfm

[3] Murray L, Sinclair D, Cooper P, et al. The socioemotional development of 5-year-old children of postnatally depressed mothers. Journal of Child Psychology and Psychiatry. 1999; 40: 1259-1271. PMid: 10604404. http://dx.doi.org/10.1111/1469-7610.00542 
[4] Bifulco A, Moran P, Ball C, et al. Childhood adversity, parental vulnerability and disorder: Examining inter-generational transmission of risk. Journal of Child Psychology and Psychiatry. 2002; 43: 10751086. PMid: 12455928 . http://dx.doi.org/10.1111/1469-7 610.00234

[5] Elgar FJ, Mills RS, McGrath PJ, et al. Maternal and paternal depressive symptoms and child maladjustment: The mediating role of parental behavior. Journal of Abnormal Child Psychology. 2007; 35: 943-955. PMid: 17577659. http://dx.doi.org/10.1007/s10 802-007-9145-0

[6] Murray L, Cooper P, Hipwell A. Mental health of parents caring for infants. Archives of Women's Mental Health. 2003; 6: 71-77. PMid: 14615925. http://dx.doi.org/10.1007/s00737-003 -0007-7

[7] Hosman CMH, Van Doesum KTM, Van Santvoort F. Prevention of emotional problems and psychiatric risks in children of parents with a mental illness in the Netherlands: I. The scientific basis to a comprehensive approach. Australian e-Journal for the Advancement of Mental Health. 2009; 8: 250-263. http://dx.doi.org/10.5172 /jamh.8.3.250

[8] Beardslee WR, Wright EJ, Gladstone TR, et al. Long-term effects from a randomized trial of two public health preventive interventions for parental depression. J Fam Psychol. 2007; 21: 703-13. PMid: 18179342. http://dx.doi.org/10.1037/0893-3200.21.4.7 03

[9] Goodman SH, Rouse MH, Connell AM, et al. Maternal depression and child psychopathology: a meta-analytic review. Clin Child Fam Psychol Rev. 2011; 14: 1-27. PMid: 21052833. http://dx.doi.o $\mathrm{rg} / 10.1007 / \mathrm{s} 10567-010-0080-1$

[10] Wodtke GT, Harding DJ, Elwert F. Neighborhood effects in temporal perspective: The impact of long-term exposure to concentrated disadvantage on high school graduation. American Sociological Review. 2011; 76: 713-736. PMid: 22879678. http://dx.doi.org/10.11 $77 / 0003122411420816$

[11] Heckman JJ, LaFontaine PA. The American high-school rate: Trends and levels. The review of economics and statistics. 2010; 92: 244-262. PMid: 20625528. http://dx.doi.org/10.1162/rest.2010.1 2366

[12] Siegenthaler E, Munder T, Egger M. Effect of preventive interventions in mentally ill parents on the mental health of the offspring: systematic review and meta-analysis. Journal of the American Academy of Child and Adolescent psychiatry. 2012; 1: 8-17. http://dx.doi.org/10.1016/j.jaac.2011.10.018

[13] Maybery D, Reupert A, Patrick K. Prevalence of children whose parents have a mental illness. Psychiatric Bulletin. 2009; 33: 22-6. http://dx.doi.org/10.1192/pb.bp.107.018861

[14] Torvik FA, Rognmo K. Barn av foreldre med psykiske lidelser eller alkoholmisbruk: Omfang og konsekvenser [Children of mentally ill parents: prevalence and consequences]. The Norwegian Institute on Public Health; 2011. 4 p. ISBN: 978-82-8082-461-5. Available from: http://www.fhi.no/dokumenter/0d04decc0b.pdf

[15] Kowalenko NM, Mares SP, Newman LK, et al. Family Matters: Infants, Toddlers and Preschoolers of parents affected by mental illness. Early interventions targeting adverse influences on young children and their parents can improve children's outcomes. Medical Journal of Australia Open. 2012. http://dx.doi.org/10.5694/mjao12. 10553

[16] Lindboe K. Barnevernloven [The child protection act]. Oslo: Gyldendal Academic Publisher; 2011.

[17] Norwegian Directorate for Children, Youth and Family Affairs. Child welfare services in Norway. 2015. Available from: http: //www. bufetat.no/engelsk/bufdir/

[18] Reedtz C, Mørch L, Lauritzen C. Registreres psykiatriske pasienters barn i elektronisk pasientjournal? -Kritisk søkelys på implementering av ny klinisk praksis i psykisk helsevern for voksne [Are children of mentally ill parents registred in the electronic patient journals?] Nordisk sygepleieforskning [Nordic Nursing Research]. 2015; 1: $36-45$.

[19] The Ministry of Health and Care Services. Changes in the Law. 2009. Available from: http://www.regjeringen.no/pages/2188713 /PDFS/OTP200820090084000DDDPDFS.pdf

[20] Darlington Y, Feeney JA, Rixon K. Interagency collaboration between child protection and mental health services: Practices, attitudes and barriers. Child abuse and neglect. 2005; 29: 1085-1098. http://dx.doi.org/10.1016/j.chiabu.2005.04.005

[21] Thistlethwaite J. Interprofessional education: a review of context, learning and the research agenda. Medical Education. 2012; 46: 5870. http://dx.doi.org/10.1111/j.1365-2923.2011.04143 . $\mathrm{x}$

[22] Mayberry D, Goodyear M, Reupert A. The Family-Focused Mental Health Practice Questionnaire. Archives of Psychiatric Nursing. 2011; 1-10.

[23] World Medical Association. Ethical Principles for Medical Research Involving Human Subjects. The Helsinki declaration. 2008. Available from: http://www . wma.net/en/30publications/10 policies/b3/17c.pdf

[24] Lacey A, Luff D. Qualitative Data Analysis. Published by Trent Focus. 2001. Available from: http://www.dcc.unicamp.br/ wainer/ cursos/2s2009/Qualitative\%20Data\%20Analysis.pdf

[25] Forman EM, Herbert JD, Moitra E, et al. A randomized controlled effectiveness trial of Acceptance and Commitment Therapy and Cognitive Therapy for anxiety and depression. Behavior Modification. 2007; 3(61): 772-99. PMid: 17932235. http://dx.doi.org/10. $1177 / 0145445507302202$ 